\title{
GROWTH RATE OF DIFFERENT BASAL CELL CARCINOMA SUBTYPES
}

4

5 Short title: Basal cell carcinomas growth rate

6 Roberto BETTI ${ }^{1}$, Laura MONEGHINI ${ }^{2}$, Elisabetta Teodolinda MAPELLI ${ }^{1}$, Gaetano BULFAMANTE ${ }^{2}$ 7 and Amilcare CERRI ${ }^{1}$

8

91 Dermatological Clinic, Department of Health Sciences, University of Milan, AO Santi Paolo e Carlo, Milan, 10 Italy.

112 Department of Health Sciences, Division of Pathology, University of Milan, AO Santi Paolo e Carlo, 20142

12 Milan, Italy

13 Corresponding author: Roberto Betti, Dermatologic Clinic, Department of Health Sciences, University of

14 Milan, AO Santi Paolo e Carlo, Via di Rudinì 8, 20142, Milan, Italy.

Phone : 00390281844321

Mail: berbet@alice.it

18 Number of words: 695

19 Number of figures: none

20 Number of tables: one

21 References: 10 
3 Basal Cell Carcinoma (BCC) subtypes seem to have different biological behaviour [1,2]. The speed of growth

4 of tumours is one of the factors that can account for their tissue invasiveness. Interviewing patients

currently is the only method of measuring the growth of a tumour over time[3,4]. Studies on BCCs' speed of growth have been carried out on rare occasions [5] and they never concerned the speed of the different BCC subtypes.

\section{Patients and Methods}

Patients affected by BCCs were studied by Our Clinic between January 01, 2015 and December, 2015. BCC subtypes were classified according to the simplified classification under superficial, infiltrativemorpheaform/micronodular and nodular subtypes. We measured the maximum lateral and depth extension of the surgically removed tumours in millimetres of the histological sample. We quantified the kinetics of the visible according to a simplified method [3]: each patient was only asked to recall the date (T1) they had first noticed a lesion where the BCC developed later and the time of surgical excision (T2). The rate of growth (ROG) is defined as the ratio between the maximum lateral extension and/or depth in millimetres $(\mathrm{mm})$ of the tumour and the time of tumour growth in months (mo) (T2-T1). Inclusion criteria: complete surgical excision. Exclusion criteria: mixed histology BCCs and inability to provide precise information about ROG. Statistical analyses were performed using SPSS for Windows (version 15.0; SPSS Inc. Chicago, II, USA), BCC subtype groups were compared using the student t-test for differences in ROG and the value of $P<0.05$ was considered significant.

\section{Results}

A total of 127 patients with BCCs were summoned; of these, 83 refused to participate or their answers were judged as poorly reliable. The remaining 44 patients ( 23 male, 21 female) were hence enrolled in the 
study. Age of the patients in years: superficial subtype $66.13 \pm+10.88$; nodular subtype $69.94 \pm 9.34$;

infiltrative subtype $74.42 \pm 8.58$ ( $p<0.04$ vs. superficial subtype.) The table shows respectively the values of depth and lateral extension in millimetres in the observed subtypes (Table 1, upper part) and the ROG of the same subtypes (Table 1, lower part).

\section{Discussion}

Although BCCs are said to take years to double in size [1], direct evidence of BCC growth rate is lacking. More recently, Kricker et al. have investigated the growth rate of BCCs [5] and stated that superficial and infiltrative/micronodular subtypes were more at risk of spreading extensively. The rate of growth (ROG) is currently the only method of measuring the growth of a tumour over time [6]; this method was then externally validated, thus confirming its usefulness [7] . Our results indicate a significant difference among infiltrative/micronodular and nodular subtypes versus superficial ones as regards the depth extension and a difference in lateral extension of the nodular subtype vs. the superficial one. This observation is consistent with the usual clinical view and histological confirmation. On the contrary the lateral extension has the highest value in the superficial subtype and the lowest in the nodular one. These observations seem to be the effect of the different ROGs measured. There is indirect evidence supporting the hypothesis that local conditions may favour a certain subtype $[8,9]$. These conditions may restrain the depth development of superficial subtypes as well as speed up the nodular or infiltrative ones. Sun-damaged skin may represent a tissue permissive stoma environment for nodular and more aggressive subtypes, which have a well-known preference for sun-exposed sites [12]. With ageing and cumulative environmental assault, senescent cells build up in the stoma and secrete factors that can disrupt tissue architecture and/or stimulate cells to proliferate. Local conditions (sun-exposed skin, increasing age) may effect the higher ROG of these more aggressive subtypes vs. the superficial one. The main limitation of this study concerns the medical history criteria used for the evaluation of the ROG, which nevertheless remains the only method currently possible to assess the growth speed of a tumour. ROG also assumes that tumour growth is constant and linear. Another limitation regards the number of patients and the high percentage of data that was lost, although 
we did not admit the great number of patients, who were unable to provide precise information, to the study.

Acknowledgments: we are grateful to Miss Giulia Turati for the technical cooperation.

Financial support: NONE

Conflict of interests: NONE

References

1. Miller SJ. Biology of basal cell carcinoma (Part I). J Am Acad Dermatol $1991 ; 24(1)$ : 1-13. Review

2. Robinson JK, Fisher SG. Recurrent basal cell carcinoma after incomplete resection. Arch Dermatol 2000 ; 136(11): 1318-24.

3. Grob JJ, Richard MA, Gouvernet J, et al. The kinetics of the visible growth of a primary melanoma reflects the tumor aggressiveness and is an independent prognostic marker: a prospective study. Int J Cancer 2002 1; 102(1): 34-38

4. Liu W, Dowling JP,Murray WK et al. Rate of growth in melanomas: characteristics and associations of rapidly growing melanomas. Arch Dermatol 2006;142 (12) 1551- 1558

5. Kricker A, Armstrong B, Hansen V, Watson A, et al. Basal cell carcinoma and squamous cell carcinoma growth rates and determinants of size in community patients. J Am Acad Dermatol $2014 ; 70(3): 456-64$

6. Lipsker D. Growth rate, early detection, and prevention of melanoma: melanoma epidemiology revisited and future challenges. Arch Dermatol 2006;142(12):1638-40.

7. Lin MJ, Mar V, McLean C, Kelly JW. An objective measure of growth rate using partial biopsy specimens of melanomas that were initially misdiagnosed. J Am Acad Dermatol 71(4):691-7,2014

8. Betti R, Inselvini E, Carducci $M$, Crosti C. Age and site prevalence of histological subtypes of basal cell carcinomas. Int J Dermatol 1995 Mar;34(3):174-6.

9. McCormack CJ, Kelly JW, Dorevitch AP. Differences in age and body site distribution of the histological subtypes of basal cell carcinoma. A possible indicator of differing causes. Arch Dermatol 1997 ; 133(5):593-6.

10. Kaur $P$, Mulvaney $M$, Carlson JA. Basal cell carcinoma progression correlates with host immune response and stomal alterations: a histological analysis. Am J Dermatopathol 2006 ;28(4):293-30 
Table 1: Mean depth and lateral extension in millimetres of the BCC subtypes studied. In the lower part of 4 the table are indicated the mean Rates of Growth in millimetres/month of the same subtypes considered.

\begin{tabular}{llllll}
\hline BCC Subtypes & & Depth Extension $(\mathrm{mm})$ & $\mathbf{P}$ & Lateral extension $(\mathrm{mm})$ & $\mathbf{p}$ \\
\hline Infiltrative & $\mathrm{n}=12$ & $3.02+2.3$ & $0.3^{\circ}$ & $5.29+2.62$ & $0.11^{\circ}$ \\
\hline Nodular & $\mathrm{n}=17$ & $2.32+1.18$ & $\mathbf{0 . 0 0 0 1 ^ { * * }}$ & $3.98+1.70$ & $\mathbf{0 . 0 2 5 * *}^{* *}$ \\
\hline Superficial & $\mathrm{n}=15$ & $0.895+0.49$ & $\mathbf{0 . 0 0 1 8 ^ { * }}$ & $5.83+2.69$ & $0.6^{*}$ \\
\hline BCC Subtypes & & $\begin{array}{l}\text { ROG for depth extension } \\
\mathrm{mm} / \text { month }\end{array}$ & & $\begin{array}{l}\text { ROG for lateral extension } \\
\text { mm/month }\end{array}$ \\
\hline Infiltrative & $\mathrm{n}=12$ & $0.195+0.13$ & $0.4^{\circ}$ & $0.377+0.40$ & $0.6^{\circ}$ \\
\hline Nodular & $\mathrm{n}=17$ & $0.278+0.32$ & $\mathbf{0 . 0 2 * *}$ & $0.464+0.5$ & $0.7^{* *}$ \\
\hline Superficial & $\mathrm{n}=15$ & $0.075+0.08$ & $\mathbf{0 . 0 0 8 ^ { * }}$ & $0.402+0.4$ & $0.8^{*}$
\end{tabular}

$5{ }^{\circ} \mathrm{p}$ value of Infiltrative-Micronodular subtype versus Nodular subtype

$6 \quad * p$ value of Infiltrative-Micronodular subtype versus Superficial subtype

$7 \quad * * \mathrm{p}$ value of Nodular subtype versus Superficial subtype

$8 \quad n=$ number of patients

9 